\title{
Basic Environmental and Engineering Geology
}

\author{
F. G. Bell
}

At the beginning of 2007, Whittles Publishing Ltd published the book Basic Environmental and Engineering Geology. The author, Professor Fred G. Bell, is a well-known engineering geologist with many years of experience who has written 20 books and over 200 papers. He integrated into this book his experience whole, not aimed only to graduates and postgraduates in geology, but also to all other experts within geography, civil engineering, environmental science and planning, whose scientific and professional interest is related to natural environment.

Hardback edition (ISBN 978-1904445-02-9), $24 \times 17 \mathrm{~cm}$, contains 325 pages with lots of text, numerous photographs, tables and various graphic appendices. Since it was written in the form of a textbook, references through the text are omitted, but at the end of the book, the author recommend literature for further reading, as well as a list of journals of interest dealing with environmental and engineering geology.

The first chapter Basic geology is written primarily for non-geologists. 42 pages of this part offer basic explanations of igneous, metamorphic and sedimentary rocks, stratigraphy and stratification, geological structures and weathering.

The next chapter, Geology and planning emphasizes importance of geology in spatial planning and human activities. Author points out the role of maps in representing geological data, specially applied maps used by spatial planners. This part also introduces problems of geological hazards, risk assessments and conservation and restoration of the land where men have already intervened.

The chapter Natural geohazards deals with natural processes that directly cause destruction of property or human casualties: volcanic activity, earthquakes, slope movements, river actions and flooding, marine and wind action, glacial hazards, dissolution of rocks and gases emanations. Impact of geohazards is dependent not only on the magnitude of the event, its duration, the area affected and the frequency with which the event occurs, but also on the vulnerability of the property.

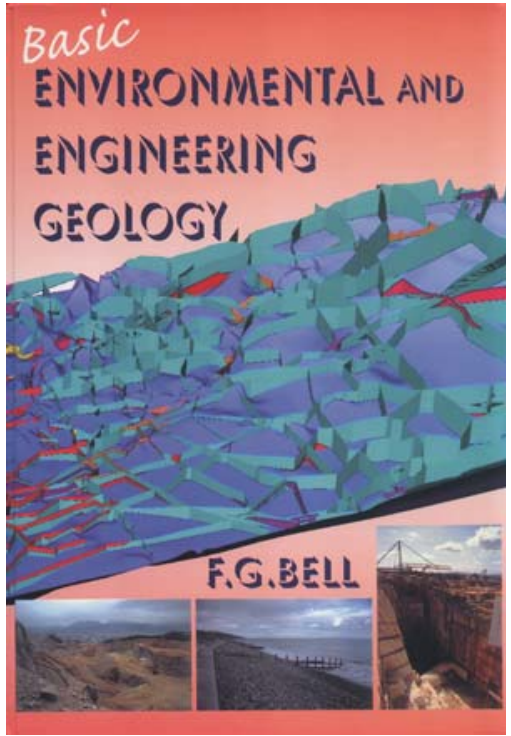

After the introduction on basic hydrology and hydrogeology, in the fourth chapter Water resources the author discusses demands and problems in dams and wells construction, as well as conjunctive use of surface and groundwater. Water quality and groundwater monitoring issues, together with saline intrusions into the coastal aquifers and nitrate pollution threat are in focus of this part, too.

The chapter Soil and the environment also starts with basic pedological terms and phenomena, and continues with detailed discussion on soil erosion, its control and conservation practices, desertification and irrigation.

Throughout the sixth chapter Mining and environment mostly the negative consequences of mining are highlighted like waste materials including waste water, subsidence, slope movement, etc. Furthermore, special attention is paid to natural oxidation of sulphide minerals with formation of sulphuric acid which drains to the underground, spontaneous combustion due to oxidation of coal exposed to air, problems of mineral dust and gases emission, dereliction and restoration of mining sites.

Waste, contamination and the environment is the theme of the seventh chapter, which deals with disposal of all kinds of waste products of modern civilization and points to advantages and disadvantages of different locations according to their (hydro)geological settings.

The next chapter, Land evaluation and site assessment comprises methods employed for analyses of particular characteristics of the location in order to estimate its suitability for certain activities, mainly construction.

Remote sensing methods are explained quite comprehensively, and among in situ methods, the author concentrates mostly on geophysical explorations.

Last three chapters almost exclusively consider engineering geology, so in the ninth part Engineering aspects of soils and rocks, readers are introduced to coarse-grained soils, silts, loess, laterite, glacial soils, peat and some most frequent igneous, metamorphic and sedimentary rocks.

Gravel, sands, clays, building stones and other materials are described in the tenth chapter titled Geology and construction materials, while the last part Geology and construction encompasses influences of particular geological features and terrain characteristics on construction of tunnels, bridges, highways, embankments and foundation for buildings.

The book ends with a list of publications recommended for Further reading, Glossary with more than 150 terms and a very detailed Index.

Wide range of information, specially tables with various classifications are supplemented with numerous photos taken worldwide illustrating practically every issue considered in this book. Unfortunately, quality of photos of landscapes printed in black and white technique, i.e. in greyscale, is rather poor, sometimes even so bad that the scenes are unrecognizable. Anyway, in spite of this omission, the book will probably be well-accepted as a geological textbook, as well as a manual designed for experts whose professions involve geological issues. Regrettably, it is unlikely that a Croatian edition of this valuable publication will be released. 


\title{
Basic Environmental and Engineering Geology
}

\author{
F. G. Bell
}

Početkom 2007. nakladnička kuća Whittles Publishing izdala je knjigu Basic Environmental and Engineering Geology. Autor knjige, profesor Fred G. Bell, istaknuti je inženjerski geolog, čija bibliografija sadrži 20 knjiga i preko 200 znanstvenih i stručnih radova. Svoje bogato iskustvo pretočio je u ovo dijelo namjenjeno ne samo studentima diplomskih i poslijediplomskih studija geologije, već i svim ostalim stručnjacima unutar geografije, građevinarstva, zaštite okoliša, prostornog planiranja i sl. čiji je znanstveni i stručni interes vezan uz prirodni okoliš.

Knjiga je tvrdog uveza (ISBN 978-1904445-02-9), dimenzija $24 \times 17 \mathrm{~cm}$ i sadrži 325 stranica gustog teksta, popraćenog brojnim fotografijama, tablicama i različitim grafičkim prilozima. Kako je pisana u obliku udžbenika, dakle bez referenci radova drugih autora čija su djela korištena tijekom pisanja, autor je na kraju knjige za svako poglavlje dao bibliografski popis radova s preporukom za daljnje čitanje kao i pregled relevantnih znanstvenih časopisa koji se bave problematikom geologije okoliša i inženjerske geologije.

Prvo poglavlje Osnove geologije namijenjeno je čitateljima čija temeljna struka nije geologija, te su na 42 stranice vrlo iscrpno objašnjeni osnovni pojmovi, procesi i pojave iz područja petrologije magmatskih, sedimentnih i metamorfnih stijena kao i iz strukturne i stratigrafske geologije, a posebno je izdvojeno i potpoglavlje o trošenju stijena.

U drugom poglavlju naslovljenom Geologija i planiranje, naglašavajući bitnu ulogu geologije pri prostornom planiranju i organiziranju ljudskih aktivnosti u prostoru, autor ukazuje na važnost karata pri prezentiranju geoloških podataka, te zasebno obrađuje različite specijalne (namjenske) karte koje su od osobitog interesa prostornim planerima. U ovom se poglavlju čitatelje upoznaje i s geološkim hazardima i rizicima koji se mogu očekivati u prirodnom okolišu, te o problemima zaštite ili 'povratka na staro' područja u kojima je čovjek već intervenirao.

U poglavlju Prirodni geohazardi obrađeni su oni geološki procesi koji izravno utječu na ljudski okoliš uzrokujući materijalne ili ljudske gubitke: vulkanska aktivnost, potresi, klizanje tla, djelovanje rijeka i poplave, utjecaji mora, vjetra i leda, otapanje stijenske mase koje rezultira urušavanjem terena te prirodne emanacije plinova. Pri procijeni utjecaja ovih prirodnih procesa na određenom prostoru uzima se u obzir njihova magnituda, trajanje, područje utjecaja i učestalost, no isto tako i vulnerabilnost objekata ili aktivnosti koje se planiraju.

U četvrtom poglavlju Vodni resursi, uz temeljne napomene o hidrologiji i hidrogeologiji, autor se osvrće na zahtjeve probleme pri izgradnji brana i zdenaca te kombiniranom korištenju površinskih i podzemnih zaliha vode. Izdvojene su i teme o kvaliteti vode, njenom praćenju (monitoring), te o onečišćenju, s naglaskom na zagađenje nitratima kao i na intruzije morske morske vode u priobalnim vodonosnicma.

Poglavlje Tlo i okoliš također počinje upoznavanjem s osnovnim pedološkim pojmovima i procesima, dok se u nastavku detaljnije diskutira o eroziji tla vodom i vjetrom, njenoj kontroli i ulozi vegetacije u njenom spriječavanju, te o dezertifikacij i navodnjavanju.

U šestom poglavlju Rudarenje i okoliš uglavnom je dan naglasak na negativne posljedice rudarenja, površinskog i podzemnog, kao što su odlaganje velikih količina jalovine i otpadnih voda u okolišu, urušavanje, klizanje i tonjenje tla i dr. Kao problemi rudarenja izdvojeni su još i oksidacija sulfidnih spojeva i stvaranje sumporne kiseline koja se drenira u podzemne vode, samozapaljenja ležišta ugljena usljed oksidacije ugljena, opasnosti od emisije plinova i mineralne prašine, te napuštanje kopova i potreba njihovog saniranja.

Otpad, zagađivanje i okolis tema je sedmog poglavlja u kojem se problematizira odlaganje svih otpadnih produkata suvremene civilizacije i ukazuje na prednosti i nedostatke određenih (hidro)geoloških značajki terena za lociranje odlagališta.

U osmom poglavlju naslovljenom Procjena zemljišta i ocjena lokacije obu- hvaćene su metode kojima se analiziraju različite značajke lokacija da bi se procijenila njihova pogodnost za određene aktivnosti, uglavnom građevinske. Prilično su detaljno pojašnjene metode daljinskih istraživanja (skeniranje u infracrvenom dijelu spektra, radarsko snimanje, ostale vrste satelitskih snimanja, aerofotogrametrija i dr.), dok među in situ metodama najviše pozornosti autor daje geofizičkim mjerenjima.

U posljednja tri poglavlja, težište je gotovo potpuno na inženjerskoj geologiji, te se u devetom poglavlju Inženjerski aspekti tla i stijena pojedinačno analiziraju podloge različitih fizičko-mehaničkih svojstava npr. grubozrnata tla, praškasta tla, gline, lateriti, glacijalna tla, treset itd., te pojedine vrste magmatskih, metamorfnih i sedimentnih stijena.

Deseto poglavlje Geologija i građevinski materijali daje pregled prirodnih materijala koji se koriste u gradnji kao što su šljunci, pijesci, gline, arhitektonski i građevinski kamen itd., dok se u jedanaestom poglavlju Geologija i građenje pojašnjava utjecaj određenih geoloških značajki terena pri gradnji tunela, mostova, cesta, riječnih nasipa i temelja zgrada.

Knjiga završava ranije spomenutim popisom literature za daljnje čitanje, Rječnikom koji sadrži preko 150 manje poznatih pojmova te vrlo detaljnim Indeksom.

Širok raspon informacija, posebno tabličnih prikaza različitih klasifikacija, upotpunjen je brojnim fotografijama lokaliteta iz cijelog svijeta koje ilustriraju gotovo svaku obrađenu temu u ovoj knjizi. Nažalost, velik broj fotografija prirodnog okoliša u crno-bijeloj tehnici, odnosno sivim tonovima, puno gubi na kvaliteti, poneke čak u tolikoj mjeri da je teško razaznati o čemu se zapravo radi. No, i uz ovaj propust, knjiga će najvjerojatnije biti dobro prihvaćena i kao udžbenik na geološkim studijima i kao priručnik namijenjen svim ostalim stručnjacima i znanstvenicima čije područje rada zadire u geološku tematiku. Nažalost, slabi su izgledi da jedno ovakvo izdanje dobijemo prevedeno i na hrvatski jezik. 